\title{
Research frontiers highlighted in Science China Life Sciences in 2009
}

\author{
CHANG ZengYi* \\ School of Life Sciences, Peking University, Beijing 100871, China
}

Received October 20, 2010; accepted October 22, 2010

Citation: $\quad$ Chang Z Y. Research frontiers highlighted in Science China Life Sciences in 2009. Chinese Sci Bull, 2010, 55: 4208-4210, doi: 10.1007/s11434-0104229-6

The Science China series celebrated their 60th anniversary of publication in 2010. In this context, Science in China Series $C$-Life Sciences has been officially changed to Science China Life Sciences (SCLS). As a prelude, the year 2009 was a year of change for $S C L S$, with the formation of an internationally-constituted editorial board, more articles contributed by internationally recognized authors, and a new design and layout for the journal. The year 2009 definitely marked a new beginning for Science China Life Sciences [1], preparing the journal for greater international recognition and impact.

Throughout the year 2009, 5 issues of the journal were published focusing on special topics, covering: genomics [2], microRNA [3], epigenetics [4], avian influenza virus [5] and stem cells [6]. In addition, one issue was dedicated to the memory of Prof. Ray Wu, a well-known Chinese-American biochemist who was a pioneer in DNA sequencing and developed the US-China bilateral Ph.D. program in biochemistry and molecular biology, i.e, the CUSBEA Program [7,8].

\section{Genomics}

Chinese scientists have made a major contribution to human and rice genome sequencing $[9,10]$. Their various contributions were summarized in the opening editorial of the January 2009 issue of Science China Life Sciences which focused on genomics [2]. In addition, the following aspects were covered: DNA microarray and next generation DNA sequencing technologies [11], genotyping technologies [12]; genomic research in liver cancer [13], epigenetic research

*Corresponding author (email: changzy@pku.edu.cn) for heterocarcinomagenesis [14], immunology in the genomic era [15], genomic research for important pathogenic bacteria in China [16] and the genomics of environmental and industrial microorganisms [17]. These comprehensive articles provided readers with an in-depth picture of recent progress in genomics research.

\section{2 microRNA (miRNA)}

RNA of small sizes were found to act as effective regulators of transcription or translation, first in C. elegans [18] and later in all types of organisms. Such RNA molecules have been designated as microRNA (miRNA) or non-coding RNA [3,19]. Review articles published in the March 2009 issue of Science China Life Sciences focused on this topic, covering the following aspects: roles of non-coding RNA in the acquisition of genomic imprinting in mammals [20], miRNA in cell differentiation and development [21], in plant development [22], in leukemia [23] and the diversity and evolution of miRNA gene clusters [24]. Also included in this special issue were review articles about the structure and function of catalytic RNAs [25], tRNAs as regulators of gene expression [26] and regulation of mammalian premRNA splicing [27]. These articles presented a comprehensive understanding of the functions of RNA molecules unveiled over the past two decades.

\section{Epigenetics}

Another active field of research in life sciences is epigenetics, which studies how heritable phenotype changes occur without involving any alteration in the genomic DNA se- 
quences of the organism. The April 2009 issue of Science China Life Sciences focused on this topic [4], with 3 review articles contributed by colleagues from Harvard (Prof. Yang Shi's laboratory), the University of California-Berkeley (Prof. Lin He's laboratory) and the University of California Riverside (Prof. Jiankang Zhu's laboratory), respectively focusing on histone methylation and demethylation [28], gene silencing resulting from the action of microRNA [29] and RNA-directed DNA methylation and demethylation [30]. These top quality reviews introduced readers to an area of genetic research which has the potential to increase understanding of many complex phenomena of living organisms.

\section{Avian influenza virus}

The potential of the avian influenza virus to adapt to human hosts caused great concern throughout the world in the recent past. The May 2009 issue of Science China Life Sciences focused on this topic [5]. Areas covered include the following: human avian influenza A (H5N1) virus infection in mainland China [31,32], human influenza A H5N1 infections in Hong Kong [33], interspecies transmission and host restriction of avian $\mathrm{H} 5 \mathrm{~N} 1$ influenza virus [34], structure and sequence analysis of influenza A virus nucleoprotein [35], structure-function of the influenza virus RNA polymerase PA subunit [36], molecular pathogenesis of the avian influenza H5N1 [37], ways for H5N1 to enter the host cells [38] and website information and bioinformatics about this virus [39]. These review articles were highly valuable for enhancing understanding both the biology and clinical background of this virus.

\section{Stem cells}

Stem cell studies attracted considerable attention from the general public, due to its potential for human therapy. The July 2009 issue of Science China Life Sciences focused on this topic [6]. Articles about this topic covered the following aspects: human parthenogenetic embryonic stem cells [40], mesenchymal stem cells [41], potential cell therapy for Parkinson's disease [42], generation of pancreatic islet cells from human embryonic stem cells [43] and induced pluripotent stem cells [44]. These reviews enabled readers to better comprehend the potential of stem cells for human clinical therapy.

\section{In memoriam of Prof. Ray Wu}

Professor Ray Wu, the Liberty Hyde Bailey Professor of Molecular Biology and Genetics at Cornell University, was a prominent scientist who pioneered techniques to deter- mine DNA sequences and genetic engineering in plants [7,8]. He suddenly passed away on February 10, 2008 in Ithaca, New York. The February 2009 issue of Science China Life Sciences was published in memory of this great biological researcher. A series of moving articles were contributed by his family members, former students and colleagues, recalling his life and his contributions to scientific research and education [45-55]. Also published in this special issue was a highly comprehensive review article concerning the assembly and structure of protein phosphatase 2A [56], contributed by Prof. Yigong Shi, who was formerly a professor at Princeton University and is currently at Tsinghua University in Beijing, China.

The journal Science China Life Sciences was formerly the one in which leading Chinese scientists would submit their finest quality manuscripts, in other words, the journal of choice. However, this has changed since the opening up of China to the outside world during the past 3 decades. China's notable economic achievements have facilitated a substantial increase in its scientific research. This in turn awakened the Chinese scientific community to revitalize the nation's scientific journals. The year 2009 was a time of considerable progress in raising Science China Life Sciences to a higher level. This was reflected by an increase in the quality of the published research papers, which represent original scientific discoveries and technological innovations reported by the authors. Raising the general quality of the journal is essential for attracting high quality manuscript submissions, which is the goal of our future efforts.

1 Wang D C. Message from the Editor-in-Chief. Sci China Ser C-Life Sci, 2009, 52: 1

2 Chen Z, Zhao G P. Human genomics in China-ten years endeavor: From planning to implementation. Sci China Ser C-Life Sci, 2009, 52: 2-6

3 Qu L H. RNomics: The new frontier in the post-genomic era. Sci China Ser C-Life Sci, 2009, 52: 193-194

$4 \mathrm{Xu}$ R M. Molecular epigenetics: Dawn of a new era of biomedical research. Sci China Ser C-Life Sci, 2009, 52: 309-310

5 Gao G F, Shaw P C. The challenges of avian influenza virus: Mechanism, epidemiology and control. Sci China Ser C-Life Sci, 2009, 52: 405-406

6 Jiang C Y. Stem cell research: From molecular physiology to therapeutic applications. Sci China Ser C-Life Sci, 2009, 52: 597-598

7 Chang Z Y. The CUSBEA Program: Twenty years after. IUBMB Life, 2009, 61: 555-565

8 Jiang C Y. Commemorating the life of a legend. Sci China Ser C-Life Sci, 2009, 52: 97-98

9 The International Human Genome Sequencing Consortium. Initial sequencing and analysis of the human genome. Nature, 2001, 409: 860-921

$10 \mathrm{Yu} \mathrm{J}, \mathrm{Hu} \mathrm{S}$ L, Wang J, et al. A draft sequence of the rice genome (Oryza sativa L. ssp. Indica). Science, 2002, 296: 79-92

11 Teng $\mathrm{X}$ K, Xiao $\mathrm{H}$ S. Perspectives of DNA microarray and next-generation DNA sequencing technologies. Sci China Ser C-Life Sci, 2009, 52: 7-16

12 Shi J X, Wang Y, Huang W. Development and application of genotyping technologies. Sci China Ser C-Life Sci, 2009, 52: 17-23

13 Han Z G. Recent progress in genomic research of liver cancer. Sci 
China Ser C-Life Sci, 2009, 52: 24-30

14 Huang J. Current progress in epigenetic research for heterocarcinomagenesis. Sci China Ser C-Life Sci, 2009, 52: 31-42

$15 \mathrm{Li} \mathrm{H} \mathrm{W}$, Li J Z, Zhao G P, et al. Current research status of immunology in the genomic era. Sci China Ser C-Life Sci, 2009, 52: 43-49

16 Yang R F, Guo X K, Yang J, et al. Genomic research for important pathogenic bacteria in China. Sci China Ser C-Life Sci, 2009, 52: 50-63

17 Wang L, Liu B, Zhou Z M. Research progress in genomics of environmental and industrial microorganisms. Sci China Ser C-Life Sci, 2009, 52: 64-73

18 Lee R C, Feinbaum R L, Ambros V. The C. elegans heterochronic gene lin-4 encodes small RNAs with antisense complementarity to lin-14. Cell, 1993, 75: 843-854

19 Bartel D P. MicroRNAs: Target recognition and regulatory functions. Cell, 2009, 136: 215-233

20 Zhang Y J, Qu L H. Non-coding RNAs and the acquisition of genomic imprinting in mammals. Sci China Ser C-Life Sci, 2009, 52: 195-204

21 Shi Y, Jin Y X. MicroRNA in cell differentiation and development. Sci China Ser C-Life Sci, 2009, 52: 205-211

22 Mao Y B, Xue X Y, Chen X Y. Are small RNAs a big help to plants? Sci China Ser C-Life Sci, 2009, 52: 212-223

23 Zhang $\mathrm{H}$, Chen $\mathrm{Y}$ Q. New insight into the role of miRNAs in leukemia. Sci China Ser C-Life Sci, 2009, 52: 224-231

24 Zhang Y F, Zhang R, Su B. Diversity and evolution of microRNA gene clusters. Sci China Ser C-Life Sci, 2009, 52: 261-266

25 Wu Q J, Huang L, Zhang Y. The structure and function of catalytic RNAs. Sci China Ser C-Life Sci, 2009, 52: 232-244

$26 \mathrm{Li}$ Y, Zhou H. tRNAs as regulators in gene expression. Sci China Ser C-Life Sci, 2009, 52: 245-252

27 Hui J Y. Regulation of mammalian pre-mRNA splicing. Sci China Ser C-Life Sci, 2009, 52: 253-260

28 Lan F, Shi Y. Epigenetic regulation: Methylation of histone and non-histone proteins. Sci China Ser C-Life Sci, 2009, 52: 311-322

29 Ma C, Liu Y F, He L. microRNAs - powerful repression comes from small RNAs. Sci China Ser C-Life Sci, 2009, 52: 323-330

30 Chinnusamy V, Zhu J K. RNA-directed DNA methylation and demethylation in plants. Sci China Ser C-Life Sci, 2009, 52: 331-343

31 Xu C L, Dong L B, Xin L, et al. Human avian influenza A (H5N1) virus infection in China. Sci China Ser C-Life Sci, 2009, 52: 407-411

32 Chen H L. H5N1 avian influenza in China. Sci China Ser C-Life Sci, 2009, 52: 419-427

33 Chan P K S. A review on human influenza A H5N1 infections in Hong Kong. Sci China Ser C-Life Sci, 2009, 52: 412-418

34 Liu D, Liu X L, Yan J H, et al. Interspecies transmission and host restriction of avian H5N1 influenza virus. Sci China Ser C-Life Sci, 2009, 52: $428-438$

35 Ng A K L, Wang J H, Shaw P C. Structure and sequence analysis of influenza A virus nucleoprotein. Sci China Ser C-Life Sci, 2009, 52:
439-449

36 Liu Y F, Lou Z Y, Bartlam M, et al. Structure-function studies of the influenza virus RNA polymerase PA subunit. Sci China Ser C-Life Sci, 2009, 52: 450-458

37 Wang H L, Jiang C Y. Avian influenza H5N1: An update on molecular pathogenesis. Sci China Ser C-Life Sci, 2009, 52: 459-463

38 Wang H L, Jiang C Y. Influenza A virus H5N1 entry into host cells is through clathrin-dependent endocytosis. Sci China Ser C-Life Sci, 2009, 52: 464-469

39 Liu D, Liu Q H, Wu L H, et al. Website for avian flu information and bioinformatics. Sci China Ser C-Life Sci, 2009, 52: 470-473

40 Hao J, Zhu W W, Sheng C, et al. Human parthenogenetic embryonic stem cells: One potential resource for cell therapy. Sci China Ser C-Life Sci, 2009, 52: 599-602

41 Wang L, Zhao R C H. Mesenchymal stem cells targeting the GVHD. Sci China Ser C-Life Sci, 2009, 52: 603-609

42 Ren Z H, Zhang Y. Cells therapy for Parkinson's disease-so close and so far away. Sci China Ser C-Life Sci, 2009, 52: 610-614

43 Zhang D H, Jiang W, Shi Y, et al. Generation of pancreatic islet cells from human embryonic stem cells. Sci China Ser C-Life Sci, 2009, 52: 615-621

44 Chen L Y, Liu L. Current progress and prospects of induced pluripotent stem cells. Sci China Ser C-Life Sci, 2009, 52: 622-636

45 Editorial. Ray Wu, Cornell's acclaimed pioneer of genetic engineering and developer of insect-resistant rice. Sci China Ser C-Life Sci, 2009, 52: 99-100

46 Wu A W, Wu C C, Sugg D K. Ray Wu's golden rules: How he achieved greatness in work and in life. Sci China Ser C-Life Sci, 2009, 52: 101-107

47 Szostak J. Ray Wu, as remembered by a former student. Sci China Ser C-Life Sci, 2009, 52: 108-110

48 Wu A S H. Eight lucky lessons learned. Sci China Ser C-Life Sci, 2009, 52: 111-114

49 Wu C W M. Remembering Ray. Sci China Ser C-Life Sci, 2009, 52: $115-117$

50 Li P. In memory of Dr. Ray Wu. Sci China Ser C-Life Sci, 2009, 52 : 118

51 Shen Y F. The China affection of Ray Wu. Sci China Ser C-Life Sci, 2009, 52: 119-124

52 Gu X C. Ray Wu and the CUSBEA Program. Sci China Ser C-Life Sci, 2009, 52: 125-127

53 Yang N S, Lan C W. For our founding father of ABRC, Prof. Ray Wu (1928-2008). Sci China Ser C-Life Sci, 2009, 52: 128-129

54 Shi Y G. Ray Wu: United we prevail. Sci China Ser C-Life Sci, 2009, 52: $130-132$

55 Tye B K. Memories of Ray Wu by a colleague. Sci China Ser C-Life Sci, 2009, 52: 133-134

56 Shi Y G. Assembly and structure of protein phosphatase 2A. Sci China Ser C-Life Sci, 2009, 52: 135-146 